\title{
Keep the epidural catheter hub sterile!
}

Editor - Epidural anaesthesia is one of the commonly practised regional anaesthetic techniques due to its inherent advantages. Insertion and maintenance of an indwelling catheter is an essential part of the technique. Catheter hub contamination with subsequent colonization of the catheter lumen and/or epidural space is an important concern among anaesthesiologists. Du Pen et al. ${ }^{1}$ and Hunt et al. ${ }^{2}$ had described hub contamination as the cause of catheter colonization in $54 \%$ and $40 \%$ of patients, respectively. Filters help in preventing foreign material from gaining access to the epidural space and to filter microorganisms present in the perfusing solution. Bacterial filters are known to decrease epidural colonization ${ }^{3}$. But epidural sets containing needle, catheter and filter are costly. It is cost effective if the sterile catheter and needles are separately procured but, the only disadvantage is the non- availability of a bacterial filter. Not to compromise on asepsis, we normally cover the hub with sterile gauze or sterile plastic cover but techniques commonly used are cumbersome and do not serve the purpose of asepsis. Hence we describe a simple method which would keep the epidural hub sterile.

After confirmation of catheter placement into the epidural space, the other side of the catheter without the hub is inserted to a fresh disposable 5 $\mathrm{ml}$ syringe without the piston. The connector is placed and catheter is put back into the syringe. The piston is placed over it and can be sealed. During the top up, with aseptic precautions, epidural hub is dropped out of the syringe by removing the piston, thereby reducing the chance of infection as shown in the figure 1 . Any number of top ups can be given and the fear of contamination will not arise even if the patient is being shifted from the postoperative ward. We agree that this may not match the absence of a filter. Still the technique can be considered for cost reasons. We state that this innovation can be considered for catheters manufactured by certain companies but may not be useful in some. We presently do not have controlled studies on this innovation on bacterial colonization of epidural catheters.

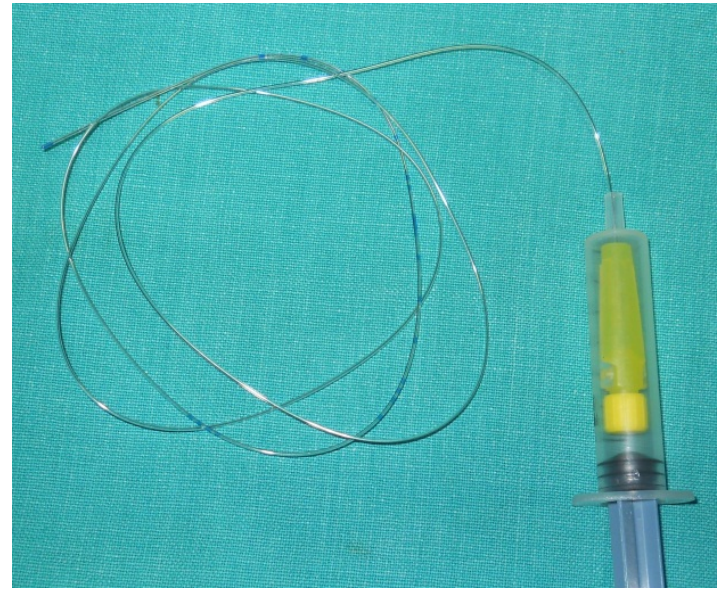

S Parthasarathy, Consultant Anaesthesiologist, Mahatma Gandhi Medical College and Research Institute, Puducherry, South India.

\section{References:}

1. Du Pen SL, Peterson DG, Williams A, Bogosian A J. Infection during chronic epidural catheterization: Diagnosis and treatment. Anesthesiology 1990;73:905-909. http://dx.doi.org/10.1097/00000542-199011000$\underline{00018}$

PMid:2240680

2. Hunt JR, Rigor BM Sr, Collins JR. The potential for contamination of continuous epidural catheters. Anesth Analg 1977;56:222225.

http://dx.doi.org/10.1213/00000539-197703000$\underline{00012}$

PMid:557918

3. James FM, George RH, Naiem H, White GJ. Bacteriologic aspects of epidural analgesia.

Anesth Analg1976;55:187-190. http://dx.doi.org/10.1213/00000539-197603000$\underline{00013}$

PMid:943977 